Indigenous Knowledge

\title{
The Violence of Colonization and the Importance of Decolonizing Therapeutic Relationship: The Role of Helper in Centring Indigenous Wisdom
}

\author{
Riel Dupuis-Rossi
}

A R T ICLE INFO

Keywords:

Indigenous cultural safety

Safety informed care

Decolonizing therapeutic alliance

Decolonizing practices around suicide

Mental health practice with Indigenous

clients

History informed care

https://doi.org/10.32799/ijih.v16i1.33223

\begin{abstract}
A B S T R A C T
Engaging existing literature and current mainstream frontline health and mental health practice, this article expands research on the impact of colonization and mainstream mental health practices on Indigenous clients. Through this process, it creates new ground on which decolonizing therapeutic responses to ongoing attempted genocide are introduced, described, and developed. I identify the brutality of historical and contemporary colonization as one of the major influences in undermining Indigenous clients' health and wellbeing - a perspective that decentres and resists individualistic pathologizing that is the focal point of mainstream psychiatric diagnoses and treatment. I also illustrate the negative impacts of psychiatric assessment for Indigenous clients and demonstrate how mainstream mental health practices, in not acknowledging colonization as the context for Indigenous clients' suffering, are implicated in ongoing enactments of colonial oppression. The mainstream assessment of Indigenous clients' suicidality as an individualized mental health disorder is also problematized. I conclude by centring Indigenous ways of knowing and culture in the promotion of health and wellbeing for Indigenous clients.
\end{abstract}

Riel Dupuis-Rossi, MA, MSW, RSW, is a therapist of Kanien'kehá:ka (Mohawk), Algonquin, and Italian descent who grew up in their traditional territories off reserve in Hamilton, Ontario, and Montreal, Quebec, Canada. Since 2011, Riel has been providing culturally-centred individual, family, couples, and group therapy to Indigenous adults in the unceded and occupied Homelands of the Squamish, Tsleil-Waututh, and Musqueam Nations. Email: rieldupuisrossi@gmail.com 


\section{Acknowledgements}

I extend respectful acknowledgement to the Squamish, Tsleil-Waututh, and Musqueam Nations and their occupied and unceded Homelands. I also extend deep respect and honouring to the Indigenous clients who informed this work. In my view, they are the true heroes. I want to honour my traditional territories, Ancestors, and relatives for holding me up and guiding me. Nia:wen.

\section{Introduction}

Canada was built on the attempted genocide and annihilation of Indigenous Peoples (Alfred, 2005; Monture-Angus, 1995 Thornton, 1987; Velez, 2019). Within the first 100 years of colonization, $95 \%$ of our relatives, who numbered in the many millions across Turtle Island, were massacred (Brave Heart \& DeBruyn, 1998; Duran \& Duran, 1995; Thornton, 1987). The "prison of grass" (Cardinal, 1969) that is the reserve system cut us off from our traditional territories, from our ways of sustaining ourselves, and from each other. The Indian Act of 1876 suppressed our governance systems, disinherited our traditional matriarchal leaders, and imposed membership and status requirements that disrupted our kinship systems (Lawrence \& Anderson, 2005; MontureAngus, 1995). The impact of colonial violence continues to reverberate. In 2018 alone, there were over 174 drinking water advisories in over 100 Indigenous reserve-based communities (Coletta, 2018). The residential school system and the Sixties Scoop-two governmental policies that interned Indigenous children in public institutions and private settler homes with the sole purpose of forced assimilation (Coates \& Wade, 2007) — stole children from their parents, extended family, and communities. Since the late 1960s, over 4,000 Indigenous women have disappeared or have been murdered in Canada (Barrera, 2019). Indigenous people make up approximately 5\% of the Canadian population but account for over $30 \%$ of the federal prison population, according to the federal government's Office of the Correctional Investigator (2020). Tens of millions of dollars are diverted from Indigenous communities and poured into Canadian institutions, organizations, and non-Indigenous foster families, giving them oversight over Indigenous affairs as intimate as raising our children and as fundamental as territorial governance (Blackstock \& Trocmé, 2005; Dupuis-Rossi, 2018; Martin \& Walia, 2019).

Colonization continues to attack our languages, philosophies, and governance structures, which have existed on Turtle Island since time immemorial. Colonial violence is at the foundation of Canada's existence. It is systemic and structural, historical and ongoing. It is pervasive and insidious (Dupuis-Rossi, 2018). Yet these historical, social, political, and economic factors are rarely acknowledged or integrated into the way mainstream health systems conceptualize Indigenous people's health and mental health needs. Nor are they given consideration when designing and delivering related services. If the systemic forces of colonization, which so profoundly impact Indigenous lives, are obscured on a daily basis, how does this affect how we, as mental health and health care workers, engage with Indigenous clients suffering the effects of colonization? 


\section{Acknowledging the Roots of Illness}

For more than a decade, I have worked with Indigenous clients who have been described by mainstream mental health services as experiencing anxiety, depression, delusional episodes, psychosis, and dissociation (Brave Heart, 1998; Duran, 2006; Timimi, 2014). Many of my Indigenous clients also live with diabetes, heart conditions, and autoimmune-related ailments such as fibromyalgia and chronic fatigue. What non-Indigenous mental health and health care systems identify as mental illness, chronic health conditions, and/or problematic behaviour, I interpret as suffering that is directly related to colonial violence and oppression, past and present. The context and the etiology of these states of psychological distress and disease is colonization (Brave Heart, 2003; Cole, 2006; Duran, 2006; Hickling, 2020). Violence sanctioned and executed by the state is "sick" and "crazy-making." For those of us who are subjected to it, it can cause us to either visit, revisit, or live in perpetual states of crisis and chaos (Dupuis-Rossi \& Reynolds, 2018).

As early as 1940, Franz Fanon, a Black/African psychiatrist, recognized that the colonizer used psychology to pathologize the colonized. In reflecting on the struggle for Algerian liberation from French colonial rule, Fanon asserted that colonial domination had a profound impact on the wellbeing of the colonized peoples (Fanon, 1963). Similarly, Indigenous Elders speak to this dynamic when they say that the social, relational, mental health, and health issues that we as Indigenous people live with today are not "our" illnesses. They did not originate with us. Historical illnesses such as the smallpox epidemic (a form of mass biological warfare that claimed many Indigenous lives) and the current social, relational, psychological, and health illnesses that Indigenous people experience today have been imposed on us. They "belong" to settler society.

Indigenous Elders from different Nations and territories teach us that we did not have cancer, diabetes, or heart disease prior to the invasion and occupation of our lands by colonial forces (Hill, 2009). We are taught by Elders that there were communal structures and protocols to deal with unstable behaviour when it manifested; however, challenges that are defined by the mainstream health system as illnesses such as schizophrenia, depression, anxiety, suicidality, psychosis, and/or dissociative conditions were non-existent. Our Elders teach us that prior to colonization, we did not have to deal with substance abuse or addictions, nor did we have to deal with child sexual abuse or domestic violence. These are the devastating impacts of genocidal violence (Brave Heart, 1998; Duran, 2006). But within the mainstream health system, colonial violence is obscured, and rather than acknowledging its negative effects on Indigenous Nations across Turtle Island, mainstream mental health systems locate the problem or pathology within Indigenous individuals, families, and communities. The process of assessing and diagnosing Indigenous pain as a personal mental health issue is normalized. In the following section, I will provide an example of how this normalization is yet another manifestation of ongoing colonial violence.

\section{Mental Health Diagnoses: The Enactment of Colonial Power on Our Minds and Hearts}

In our diverse Indigenous cultures, there are many powerful ceremonies. One of them is the naming ceremony (Duran, 2006). In a naming ceremony, an individual is given the name of an 
Ancestor or an honoured relative. The ceremonial name may also be based on the person's personality, gifts, and abilities. This given name shapes the individual's sense of self and helps to define their roles and responsibilities within the community. An Indigenous naming ceremony nourishes, uplifts, strengthens. The given name acts as guidance to the individual who wishes to respect and honour the ceremony and the name through their daily actions and behaviours.

The process of receiving a mental health diagnosis has been compared to that of a traditional naming ceremony (Duran, 2006). The Diagnostic and Statistical Manual of Mental Disorders (DSM) diagnosis ("naming") stays with people, shaping our perception of ourselves, how we define our experiences, and how others perceive who we are (Duran \& Duran, 1995; Duran, 2006). Over the last 10 years as a therapist, I have worked with many Indigenous clients who have come to me with high levels of distress after undergoing assessment and receiving a psychiatric diagnosis. The DSM diagnosis functioned to define the impact of colonial violence as a personal deficit. These psychiatric assessments and diagnoses imposed on them a label associated with profound individualized disorders such as personality disorder, anxiety disorder, or depressive disorder. Rather than the "disorder" of colonization being acknowledged, Indigenous clients and patients were left to carry a diagnostic "name" as the manifestation of their own personal deficit. The influence of ongoing colonial violence on one's mental health is disregarded. Thousands of years of peaceful co-existence on these lands are rendered invisible. Five hundred years of Indigenous resistance to colonial violence is ignored (Brave Heart, 1998; Duran, 2006; Hill, 2009; Timimi, 2014). In the eyes of the mainstream mental health system, the Indigenous client is identified as the problem and their behaviour is labelled by way of diagnosis. To many mainstream therapists, this is a normal process. To Indigenous clients, it is yet another process that normalizes the enactment of colonial power on our minds and hearts.

As someone who has worked therapeutically with Indigenous clients, I contend that psychiatric assessments and diagnoses do not serve to clarify the problem or help with solutions to the pain experienced by Indigenous clients. Instead, they are an example of how the chaos of past and present colonial violence to which Indigenous clients have been subjected is never accounted for or acknowledged by mainstream professionals. Eduardo Duran (2006) points out that the act of imposing a mental health diagnosis on an Indigenous client contributes to the "soul wounding" of colonization. Indigenous people are once again made vulnerable to the pathologizing and oppressive power and authority of being externally defined. In the case of diagnosis and different forms of mental health assessments, it is crucial to view historic and contemporary colonization as directly related to an Indigenous client's presentation and suffering. The violence that we have faced has been wielded against us by the Canadian government. It is state-based violence that has attempted to annihilate us. This is Canada's foundation. Not many of Canada's citizens - including mental health professionals - know this history, but it gets re-enacted in so many interactions that Indigenous people have with the mainstream health and mental health system from the point of first contact to the powerful point of assessment and diagnosis. In this way, professionally accepted processes of assessment and diagnoses within mainstream mental 
health services are complicit in the normalization of ongoing genocide (Coates \& Wade, 2007; Duran, 2006; Herman, 1992; Richardson \& Reynolds, 2014; Wade, 1997).

All Indigenous Peoples have, in one way or another, been touched directly or indirectly by the chaos and violence of colonization. As if surviving and resisting colonial violence is not demanding enough, when Indigenous clients reach out for support from mainstream mental health systems, they are pathologized for experiencing and manifesting its impacts. The Indigenous clients that I have worked with have been extremely psychiatrized. They have been medicated, admitted, restrained, and confined. They have been diagnosed with bipolar disorder, schizophrenia, schizoaffective disorder, borderline personality disorder, or some other severe mental health diagnosis (Briere \& Scott, 2006). These same Indigenous clients have shown up for counselling drunk, high, beaten, homeless, scared, scarred, disoriented, and in deep crisis. Over the course of therapy, these Indigenous clients reveal the extreme violence to which they have been subjected (Coates \& Wade, 2007; Herman, 1992; Richardson \& Reynolds, 2014; Wade, 1997). Many live with intimate violence and the ongoing threat of having their children apprehended (Blackstock \& Trocmé, 2005; Lawrence \& Anderson, 2005; Martin \& Walia, 2019; Monture-Angus, 1995). They live with the reality of poverty and the fear of eviction and homelessness. They live with racism and discrimination and the onslaught of negative stereotypes, police brutality, and ongoing land theft and displacement. It is this violence that is so destabilizing. It is this violence that makes it nearly impossible to function. It is the "illness" of colonial violence that inscribes itself on their souls and that is the source of their marginalization, isolation, disorganization, and instability.

What appears at first to be an inability on the part of Indigenous clients to orient to person, place, and time is soon revealed to be a struggle to articulate the formative experiences of unspeakable violence and brutality that they are struggling to survive. As I listen to Indigenous clients, deeply held shame emerges and the truth comes out. Their shame reflects a societally imposed silence about the truth of state-sanctioned torture experienced in residential schools, through the reserve system, and in the child welfare system. The reality of the violence and the desecration to which they have been subjected occurs at the most vulnerable time in their lives: as children. To recognize the violence and state-sanctioned torture of Indigenous children (Wade, 1997) at the foundation of Indigenous clients' mental health and health challenges has important implications for how the mainstream health system conceptualizes Indigenous people's service needs. It also requires a profound shift in the way that health and mental health services are designed and delivered. I have detected a desire for this shift to occur when interacting with Indigenous clients. But this is also a shift that is being called for by Indigenous and non-Indigenous mental health workers and health care providers as they are faced with the inadequacies of mainstream assessments, diagnoses, and interventions in the health of their Indigenous clients.

\section{Suicidality Is Connected to Ongoing Attempted Genocide}

Health and mental health systems also need to reconceptualize their understanding of suicidality vis-à-vis their Indigenous clients. I have witnessed the suffering of many Indigenous 
clients who have been impacted by residential schools and the so-called child welfare system as they struggled with thoughts of taking their own lives. The epidemic rates of suicide in Indigenous communities are a result of the systematic dehumanization of colonial violence wielded on a collective level (Dupuis-Rossi, 2011; Dupuis-Rossi, 2018; Dupuis-Rossi \& Reynolds, 2018). What has happened to us as Indigenous Peoples, collectively and historically, is mirrored and enacted in our own personal lives. The waves of genocidal attack, the hundreds of years of colonial desecration of our cultures, the imposed disconnection from our traditional territories, our confinement on reserves, the devastation of loss from family and community, the criminalization of sacred ceremonies, and the attacks on our loving relationships have all contributed to the epidemic rates of suicide among Indigenous people. However, insofar as genocidal violence remains hidden and obscured by settler society, including mainstream health systems, Indigenous individuals are left to carry the burdens of its disorders. The profound pain of attempted ongoing genocide remains disenfranchised; it has no witness, no acknowledgement. This is a very heavy burden for any one person to bear. It is also a heavy burden as a collective for Indigenous Peoples, for this is what was first attacked: our Nations, our territories, our ways of living. This collective burden continues to be deeply felt (Brave Heart, 2003; Brave Heart \& DeBruyn, 1998).

In order to be of benefit to Indigenous clients, mental health workers and health care providers must work with the impacts of colonization — including suicidal ideation—on their Indigenous clients. It is of utmost importance that the forces of colonization are named. The specific ways an Indigenous client is made to carry the burdens of colonial violence must be identified. Unique ways of working with Indigenous clients to externalize the burdens of colonization are central in facilitating the reconnection to a positive sense of self and Indigenous identity.

Acknowledging and naming colonial violence can help to restore a sense of self-control by revealing the often unseen colonial forces that impact one's sense of self and worth. Once the forces of colonization are named and identified, it becomes possible to externalize its burdens and place responsibility back where it belongs (Monture-Angus, 1995). This is the first step toward decolonizing our practices with Indigenous clients. As therapists and health care providers, we can critically assess the inadequacies of mainstream interventions that individualize and problematize Indigenous clients suffering the impacts of 500 years of colonial brutality. As helpers, we can turn to the wisdom of Indigenous Elders and their teachings. We can honour the courage that it takes for Indigenous clients to live beyond the wounding caused by colonization. As helpers, we can support Indigenous clients by working with them to connect to a sense of themselves as strong, loving, and brave people (Thomas \& Green, 2007).

\section{In Relationship, We Heal}

We know from the research on complex trauma that when we are violated, overwhelmed, terrorized, held captive, starved, and tortured as children, our experiences of ourselves, others, and the world around us are infused with terror and horror, helplessness, and despair (Herman, 1992; Timimi, 2014). We also know, based on this same body of research, that with safety and 
support, we can heal. However, we need to be seen, respected, and given the safe refuge and harbour that was missing in those formative years (Dupuis-Rossi \& Reynolds, 2018; Herman, 1992).

Snuneymuxw and Cowichan Elder Roberta Price speaks of this process in our Peoples' terms, when she shares with us the ability of our Elders to give unconditional love and to know that this is what is needed for our healing and for the recovery of our wholeness. As Indigenous people, it is our right to be loved and our right to love that needs to be recovered and reclaimed.

Staying present for this kind of healing process challenges every defence, every escape, every choice, every bit of power and authority that we have and hold on to as mental health workers and health care providers. It challenges us to be human and to let go of all other pretense except the good medicine of listening, witnessing, and remaining deeply present. It transforms us from being a psychotherapist, a doctor, a nurse, or a mental health worker into being a humble, caring, and deeply respectful helper.

Over my 10 years as an Indigenous therapist, I have come to appreciate that some of my Indigenous clients have benefited from psychotropic medications. In the context of a respectful relationship with a psychiatrist or general practitioner, these kinds of medications have helped some of the clients feel more internally stable, regulated, and healthy (Briere \& Scott, 2006). I have learned that nothing on the path of healing and recovery is either/or, and that as helpers we are called on to respect the Indigenous client as the expert on their own health. We are often called on to do this even when they themselves are unable to see their own wisdom. As helpers, we are tasked to listen carefully as their "expertise" emerges within the context of the safe therapeutic relationship. Respecting an Indigenous client's self-determination in their own healing process can be a profound act of decolonization.

While I have come to know the importance of keeping in mind the history of colonization, it is equally important to recognize the cultural strengths of Indigenous clients when conducting an assessment: Is the root cause of the instability in their systems biochemical, or is it sociopolitical and historical? Does the Indigenous client need psychiatric intervention such as psychotropic medication, or is a relational intervention called for? I am careful to engage with humility, which is a cultural tenet of being a helper. I avoid directing Indigenous clients in their healing; rather, I support them in their own knowing, power, and strength.

In our roles as helpers, how can we help Indigenous clients get stabilized and connected to a safe and positive sense of self and of others? Stabilization can, sometimes, mean utilizing medications, and yet it is also important to remember that advocacy and support generally go a long way. This is a relational way to work that is in line with an Indigenous worldview and vision of health. Creating a circle of care around Indigenous clients is the best medicine: drum groups, time with Elders, Healing Circles, and safe ceremonies can help our people feel connected to culture and to a positive sense of their Indigenous identities. Healthy, safe connection is in and of itself stabilizing on a very deep and profound level. Indigenous clients are an integral part of the Indigenous Circle. They are our relatives. They are loved and valued. Let them know this. 


\section{Conclusion}

When working with Indigenous clients, it is of critical importance that therapists, mental health workers, and health care providers remember that each Indigenous individual or family comes from a culture that has for tens of thousands of years been based on respect, connection, honour, and love (Brendtro et al., 1991; Brokenleg, 2012; Brokenleg \& James, 2013). In this sense, it is important to appreciate that this cultural and traditional knowing lives within us as Indigenous people. It is much stronger than the last 500 years of colonization despite the lack of connection to our territories and communities that many of our people have experienced. This lack of connection is through no fault of our own. It has been imposed on us through the reserve system, forced assimilation, and continued occupation by Canadian governments operating in the name of settler colonialism. Nonetheless, more than 500 years of Indigenous resistance has also ensured that love of kinship ties and community continue to have the potential to nourish us and to keep us alive in the wake of colonial violence and devastation. These connections and this sense of connectedness continue to live in our bones, our blood, our hearts, and our spirit, whether we grew up on reserve, off reserve, with our parents and/or grandparents, in foster care, or in settler institutions like residential schools or prisons (Carriere \& Richardson, 2009). Our ancestors and the spirit of our territories are holding us up, guiding us, and speaking to us, always. They are embedded in our cultural and traditional knowing, our connection to our territories and to each other. Through these connections, we can find what we need to heal from the devastating impacts of colonial violence and to reclaim our health, our lives, and our personal and collective power as Indigenous Peoples. Mainstream therapists, mental health workers, and health care providers are encouraged to honour our wisdom, our forms of resistance, and our strength and to act in solidarity with Indigenous Peoples by engaging in a process of decolonizing their therapeutic practices with Indigenous clients.

\section{References}

Alfred, T. (2005). Wasáse: Indigenous pathways of action and freedom. Broadview.

Barrera, J. (2019, May 31). National inquiry calls murders and disappearances of Indigenous women a "Canadian genocide." CBC News. https://www.cbc.ca/news/indigenous/genocide-murdered-missing-indigenous-womeninquiry-report-1.5157580

Blackstock, C., \& Trocmé, N. (2005). Community-based child welfare for Aboriginal children: Supporting resilience through structural change. Social Policy Journal of New Zealand, 24, 12-33. https://www.msd.govt.nz/about-msd-and-our-work/publicationsresources/journals-and-magazines/social-policy-journal/spj24/24-community-basedchild-welfare-for-aboriginal-children-supporting-resilence-through-structural-changep12-33.html

Brave Heart, M. Y. H. (1998). The return to the sacred path: Healing the historical trauma and historical unresolved grief response among the Lakota through a psychoeducational group intervention. Smith College Studies in Social Work, 68(3), 287-305. http://doi.org/10.1080/00377319809517532 
Brave Heart, M. Y. H. (2003). Historical trauma response among Natives and its relationship with substance abuse: A Lakota illustration. Journal of Psychoactive Drugs, 35, 7-13. https://doi.org/10.1080/02791072.2003.10399988

Brave Heart, M. Y. H., \& DeBruyn, L. M. (1998). The American Indian holocaust: Healing historical unresolved grief. American Indian and Alaska Native Mental Health Research, 8(2), 60-82. http://doi.org/10.5820/aian.0802.1998.60

Brendtro, L. K., Brokenleg, M., Van Bockern, S., \& Blue Bird, G. (1991). The circle of courage. Beyond Behavior, 2(2), 5-12.

Briere, J., \& Scott, C. (2006). Principles of trauma therapy: A guide to symptoms, evaluation, and treatment. Sage.

Brokenleg, M. (2012). Transforming cultural trauma into resilience. Reclaiming Children and Youth, 21(3), 9-13.

Brokenleg, M., \& James, A. B. (2013). Living in balance: A Lakota and Mohawk dialogue. Reclaiming Children and Youth, 22(2), 51-55.

Cardinal, H. (1969). The unjust society. Douglas \& McIntyre.

Carriere, J., \& Richardson, C. (2009). From longing to belonging: Attachment theory, connectedness, and Indigenous children in Canada. In S. McKay, D. Fuchs, \& I. Brown (Eds.), Passion for action in child and family services: Voices from the prairies (pp. 4967). Canadian Plains Research Center.

Coates, L., \& Wade, A. (2007). Language and violence: Analysis of four discursive operations. Journal of Family Violence, 22(7), 511-522. https://doi.org/10.1007/s10896-007-9082-2

Cole, N. (2006). Trauma and the American Indian. In T. M. Witko (Ed.), Mental health care for urban Indians: Clinical insights from Native practitioners (pp. 115-130). American Psychological Association. https://doi.org/10.1037/11422-006

Coletta, A. (2018, October 15). "Third World conditions": Many of Canada's Indigenous people cannot drink the water at home. Washington Post. https://www.washingtonpost.com/world/the_americas/third-world-conditions-many-ofcanadas-indigenous-people-cant-drink-the-water-at-home/2018/10/14/c4f429b4-bc5311e8-8243-f3ae9c99658a_story.html

Dupuis-Rossi, R. (2011). Indigenist approaches to healing Indigenous historical trauma [Unpublished master's thesis]. California State University.

Dupuis-Rossi, R. (2018). Indigenous historical trauma: A decolonizing therapeutic framework for Indigenous counsellors working with Indigenous clients. In S. Collins (Ed.), Embracing cultural responsivity and social justice: Re-shaping professional identity in counselling psychology (pp. 269-298). Counselling Concepts.

Dupuis-Rossi, R., \& Reynolds, V. (2018). Indigenizing and decolonizing therapeutic responses to trauma-related dissociation. In N. Arthur (Ed.), Counselling in cultural contexts: Identities and social justice (pp. 293-315). Springer. https://doi.org/10.1007/978-3-03000090-5_13 
Duran, E. (2006). Healing the soul wound: Counseling with American Indians and other Native Peoples. Teachers College Press.

Duran, E., \& Duran, B. (1995). Native American postcolonial psychology. State University of New York Press.

Fanon, F. (1963). The wretched of the earth. Grove Press.

Herman, J. L. (1992). Trauma and recovery: The aftermath of violence-From domestic abuse to political terror. Basic Books.

Hickling, F. W. (2020). Owning our madness: Contributions of Jamaican psychiatry to decolonizing Global Mental Health. Transcultural Psychiatry, 57(1), 19-31. https://doi.org/10.1177/1363461519893142

Hill, G. (2009). 500 Years of Indigenous Resistance. PM Press.

Lawrence, B., \& Anderson, K. (Eds.). (2005). Indigenous women: The state of our Nations [Special issue]. Atlantis: Critical Studies in Gender, Culture, and Social Justice, 29(2). https://journals.msvu.ca/index.php/atlantis/issue/view/97

Martin, C. M., \& Walia, H. (2019). Red women rising: Indigenous women survivors in Vancouver's Downtown Eastside. Downtown Eastside Women's Centre. https://dewc.ca/wp-content/uploads/2019/03/MMIW-Report-Final-March-10-WEB.pdf

Monture-Angus, P. (1995). Thunder in my soul: A Mohawk woman speaks. Fernwood Publishing.

Office of the Correctional Investigator. (2020, January 21). Indigenous people in federal custody surpass 30\%: Correctional investigator issues statement and challenge [Press release]. https://www.oci-bec.gc.ca/cnt/comm/press/press20200121-eng.aspx

Richardson, C., \& Reynolds, V. (2014). Structuring safety in therapeutic work alongside Indigenous survivors of residential schools. Canadian Journal of Native Studies, 34(2), $147-164$.

Thomas, R., \& Green, J. (2007). A way of life: Indigenous perspectives on anti oppressive living. First Peoples Child \& Family Review, 3(1), 91-104. https://doi.org/10.7202/1069529ar

Thornton, R. (1987). American Indian holocaust and survival: A population history since 1492. University of Oklahoma Press.

Timimi, S. (2014). No more psychiatric labels: Why formal psychiatric diagnostic systems should be abolished. International Journal of Clinical and Health Psychology, 14(3), 208-215. https://doi.org/10.1016/j.ijchp.2014.03.004

Velez, E. D. (2019). Decolonial feminism at the intersection: A critical reflection on the relationship between decolonial feminism and intersectionality. The Journal of Speculative Philosophy, 33(3), 390-406. https://doi.org/10.5325/jspecphil.33.3.0390

Wade, A. (1997). Small acts of living: Everyday resistance to violence and other forms of oppression. Contemporary Family Therapy, 19, 23-39.

https://doi.org/10.1023/A:1026154215299 